\title{
A busca e o uso da informação nas organizações
}

Waleska Silveira Lira

Professora da Universidade Estadual da Paraíba, Doutora em Engenharia da Produção pela Universidade Federal da Paraíba.

Gesinaldo Ataíde Cândido

Professor do Programa de Pós-Graduação em Engenharia de Produção da Universidade Federal da Paraíba-UFPB, Doutor em Engenharia de Produção pela Universidade Federal de Santa Catarina.

Geraldo Maciel de Araújo

Professor do Programa de Pós-Graduação em Engenharia de Produção da Universidade Federal da Paraíba-UFPB, Doutor em Engenharia de Produção pela Fundação Getúlio Vargas.

Marcelo Alves de Barros

Professor do Programa de PósGraduação em Engenharia de Produção da Universidade Federal da Paraíba, Doutor em Ciências da Computação, Professor da Universidade Federal de Campina Grande -UFCG.

Este estudo tem como objetivo mostrar a importância do uso eficiente da informação e do conhecimento nas organizações. Analisa as diferentes abordagens da busca e uso da informação, tendo por referencial os princípios associados à gestão da informação e do conhecimento. Conclui que o diferencial é detectar e gerenciar a informação eficaz, através do processo de busca, seleção, análise, disseminação e transformação dessa informação em conhecimento, com o objetivo de obter um melhor posicionamento no espaço competitivo no qual atua. 
Palavras-Chave: Uso; Informação; Organização.

\section{The Seeking and Use of information in the Organizations}

The objective of this study is to show the importance of the efficiency in the use of information and knowledge in the organizations. It analyses the different points of view of the information seeking and use of the information, having as a referential the principles associated to the management of the information and knowledge. Therefore can be concluded that the differential is to detect and to manage the information efficiency, through the process of information seeking, selection, analysis, dissemination and transformation of the information in knowledge with the aim to get a better position in the competitive space in which it acts.

Keywords: Use; Information; Organization.

Recebido em 09.11.2006 Aceito em 06.03.2008

\section{Introdução}

A mudança no ambiente de negócios é complexa, e pode ser analisada sob diferentes perspectivas. A nova economia está desencadeando novas formas de obter informações e traçar estratégias competitivas. Esse cenário em que as empresas estão atuando exige uma profunda reestruturação na sua conduta para resolver os problemas de gestão, e uma nova maneira de estabelecer a estratégia a ser adotada pelas empresas para se manterem competitivas em um mercado globalizado.

Nesse sentido, as informações passam a ter um papel fundamental, possibilitando melhor e mais rápida percepção das mudanças, facilitando a tomada de decisão e possibilitando um reposicionamento dos negócios com maior rapidez e agilidade de resposta às novas necessidades. Portanto, um dos principais desafios para as pessoas e para as organizações é saber detectar e gerenciar a informação eficaz, em busca de melhor posicionamento no espaço competitivo no qual atua. É no processo de busca e de uso da informação que se define a situação por meio da qual os indivíduos, dentro da organização, são expostos às informações: como eles buscam estas informações, o que leva estes profissionais a decidir usar uma determinada informação para tomar uma determinada decisão. O presente artigo discute o Impacto da Sociedade da Informação nas organizações, mostra a importância da informação e 
do conhecimento para as empresas e discute os modelos de busca e uso da informação.

\section{Impacto da sociedade do conhecimento nas organizações}

Em todos os momentos históricos da evolução humana, têm-se observado inúmeras influências nas técnicas de obtenção da informação. A necessidade do indivíduo de mudar o ambiente em que vive, imprimir suas marcas e seus pensamentos, tem por escopo a tentativa de melhorar suas condições de sobrevivência, de dominar a informação e, também, de se imortalizar com suas descobertas.

A maneira como agimos para adequar o ambiente às nossas necessidades tem um papel importante na construção de valores sociais de cada época e na forma de vida de cada ser humano. Fazendo-se uma retrospectiva, podemos citar Johannes Gutenberg, da tipografia de tipos móveis no século XVI, para observarmos que a descoberta da imprensa levou à disseminação de idéias e conhecimentos, alterando a forma de sentir e de lidar com os desafios sociais.

Pode-se citar, já no século $X X$, o uso do telefone, telégrafo, fotografia, cinema, rádio, televisão e comunicação via satélite, como também a criação da rede mundial de computadores que transformaram e estão transformando o modo como sentimos, pensamos e agimos diante do mundo.

Do ponto de vista da percepção do cidadão comum, este início de século pertence ao movimento, pertence à mudança. Tanto em extensão quanto em intensidade, as transformações envolvidas na modernidade são mais profundas do que a maioria das mudanças características dos períodos anteriores. A idéia geral de mudança, em movimento neste início de século XXI, é crucial para o entendimento da dinâmica da sociedade e das organizações. Não só as mudanças estão acontecendo, e mais rápido, mas também nossa percepção das mudanças se torna mais aprofundada pela simultaneidade entre acontecimentos e notícia propiciada pela tecnologia da informação.

O mundo global atinge todas as áreas do conhecimento, na medida em que as ações passam a ser cada vez mais direcionadas para a descoberta, ao invés de existir no sentido tradicional da instrução.

O avanço da Tecnologia de Informação influenciou profundamente o comportamento da sociedade. Verifica-se uma forte relação entre as ferramentas tecnológicas criadas pelo homem, através do aprimoramento de seu conhecimento, e a mudança de seu comportamento. Foi por meio da técnica que o homem conseguiu aperfeiçoar seus utensílios. No estágio inicial do desenvolvimento da técnica, o utensílio era um prolongamento da estrutura física. Depois, com as máquinas, a energia humana foi substituída pela mecânica, hidráulica, elétrica ou atômica. Atualmente, não só deve ampliar os atributos físicos do ser humano, mas sua inteligência, seu raciocínio, sua memória, enfim, sua capacidade mental. 
É indiscutível que o avanço tecnológico, considerado na atualidade como sendo ciência aplicada, o saber ativo, o conhecimento habilitado para atuar sobre a sociedade e transformá-la, influenciou, nos últimos séculos, todos os setores da vida humana.

Como instrumento de socialização, a informação cumpre um papel importante na forma de aplicação, de entendimento, disseminação, interpretação e transformação de conhecimento, que traz à tona a questão da influência da informação na competitividade, seja ela a nível empresarial ou de nação.

Os avanços tecnológicos estão proporcionando mudanças na economia mundial, gerando um novo padrão de competitividade em que a capacidade de gerar novas informações úteis, em intervalos de tempo cada vez menores, é o que irá fazer o diferencial competitivo para os países e para as empresas.

Estes avanços tecnológicos propiciam o surgimento de meios para a disseminação da informação e comercialização de produtos e serviços, bem como novas oportunidades de investimento. Em contrapartida, está ameaçando a existência de setores que já não encontram espaço na nova economia. Neste sentido, o mercado passa a exigir das organizações a utilização de novas estratégias de competição, maior descentralização, comunicação bilateral entre empresa/consumidor/fornecedor, com o intuito de estabelecer unidades produtivas em locais que ofereçam maior vantagem, independente de fronteiras geográficas.

Dentro deste panorama, a principal matéria-prima é a informação. A capacidade de gerar, tratar, processar, filtrar e transmitir informação impõe desta forma um grande desafio, tanto para as empresas como para os trabalhadores. O desafio é adquirir a competência necessária para transformar informações disponíveis e o conhecimento individual em ações integradas de alto valor agregado ao negócio.

O conhecimento é considerado como fator essencial, e por sua vez é adquirido através de um processo de aprendizado mútuo que requer das organizações treinamento contínuo, como também do governo investimento em políticas sociais do conhecimento, através de uma política educacional adequada à realidade local.

Todo este contexto se dá sob o impacto de um mercado globalizado, sob uma reestruturação produtiva, com aumento do fluxo de capitais internacionais e aceleração tecnológica. Este aspecto está levando a um intenso debate em torno das implicações desse processo para o ser humano.

$\mathrm{Na}$ sociedade da informação, a liberdade de pensamento e a sua expressão não podem ser exercidas de maneira integral sem 0 reconhecimento do direito à informação, na medida em que o saber determina o entendimento e as opções da consciência que irão formar as opiniões e raciocínios sobre os acontecimentos sociais. A ausência de informações faz o agente achar-se destituído de capacidade crítica para avaliar o ambiente comunitário e exprimir suas convicções. Porém, o 
direito de ser informado e de ter acesso às informações desejadas deverá ser dado de forma precisa e correta.

\section{Evolução do conceito de informação e de conhecimento}

\subsection{Informação}

A palavra informação deriva do latim, informare, significando dar forma ou aparência, criar, representar, uma idéia ou noção de algo que é colocado em forma, em ordem. Drucker (2000, p. 13) diz que a informação é "dado investido de relevância e propósito".

Informação pode ser um dado isolado ou um agrupamento organizado de dados, processado por algum tipo de tratamento coeso. Conforme Mcgee \& Prusak (1994, p. 24), informação são "dados coletados, organizados, ordenados, aos quais são atribuídos significados e contexto".

A informação é o conjunto de dados úteis às organizações e aos seres humanos, no sentido de dar subsídios para uma tomada de decisão eficaz. Davenport e Prusak (1998, p. 04) afirmam que informação é uma "mensagem, geralmente na forma de um documento ou uma comunicação audível ou visível", e que dados são transformados em informações por meio dos seguintes processos:

- Contextualização: sabemos qual a finalidade dos dados coletados.

- Categorização: conhecemos as unidades de análise ou os componentes essenciais dos dados.

- Cálculo: os dados podem ser analisados matemática ou estatisticamente.

- Correção: os erros são eliminados dos dados.

- Condensação: os dados podem ser resumidos em uma forma mais concisa.

Na visão de Barreto (1994), a informação é considerada como estruturas significantes, com a competência de gerar conhecimento no indivíduo, em seu grupo ou na sociedade.

A informação pode ser considerada um dado processado de forma significativa para o usuário e que tem valor real ou percebido para decisões correntes ou posteriores.

O processo de transformação dos dados em informação, na visão de Stair (1998, p. 5), ocorre através de "uma série de tarefas logicamente relacionadas, executadas para atingir um resultado definido".

Para Mcgee \& Prusak (1994, p. 23-04),

A informação não se limita a dados coletados; na verdade a informação são dados coletados, organizados, ordenados, aos quais são atribuídos significados e contexto. Informação deve informar, enquanto os dados absolutamente não têm essa missão. A informação deve ter limites, enquanto os dados 
podem ser ilimitados. Para que os dados se tornem úteis como informação a uma pessoa encarregada do processo decisório é preciso que sejam apresentados de tal forma que essa pessoa possa relacioná-los e atuar sobre eles.

O objetivo da informação no âmbito empresarial é habilitar a empresa a alcançar seus objetivos pelo uso eficiente dos recursos disponíveis, que são representados por pessoas, tecnologia, capital e a própria informação.

A tecnologia por si só não é capaz de transformar dados em informação, é preciso que o homem crie um significado. Portanto, a inexistência de intervenção humana faz com que a maior parte do que experimentamos seja apenas dado, e a maioria do que é chamado de tecnologia da informação seja, de fato, apenas tecnologia de dados, porque não trata da compreensão, construção ou comunicação da informação.

Desta forma, destaca-se Spender (2001), quando diz que a relação de dependência da informação com o ambiente é um sinal, cujo significado está ligado ao sistema em que está incorporado. A informação é o único recurso que não se perde com o uso ou com a disseminação. A informação só se perde quando se torna obsoleta.

Batolomé (1999) diz que o excesso de dados e a quantidade enorme de informações despejadas diariamente fazem com que a habilidade de saber selecionar o que é relevante e útil seja cada dia mais valorizada para a tomada de decisões.

Wurman (1997) enfatiza que, ao disseminar a informação, deve-se considerar o problema da "sobrecarga de informação" em sistemas informatizados, porque as pessoas têm uma capacidade limitada de processar informações e, sendo a informação a força motriz de nossa vida, pode se transformar em uma ameaça, em virtude da quantidade excessiva de informação gerada, que exige cada vez mais das pessoas, tornando-as mais ansiosas.

Essa ansiedade por informação, segundo (WURMAN, 1999), é o resultado da distância cada vez maior entre o que se compreende e o que se acha que deve ser compreendido. Existe uma lacuna entre os dados e o conhecimento, e isso ocorre quando a informação não diz o que se quer ou precisa saber.

Assimilar a informação tornou-se um problema muito maior do que disseminá-la. Tanta informação pode causar angústia, ocasionando a perca de foco ao tomador de decisões. Muitos empresários já sofrem da chamada Síndrome de Informação, por acreditarem que não estão lendo tudo o que é publicado, o que, obviamente, seria impossível (WURMAN, 1997).

\subsection{Conhecimento}

Destacado por diversos autores como um bem intangível, o conhecimento passa a ser a grande preocupação das organizações. 
Nonaka (2000) enfatiza essa preocupação, quando mostra a importância da participação das pessoas nas suas definições de conhecimento e quando afirma que os seres humanos são necessários para a criação de conhecimento: os novos conhecimentos sempre se originam nas pessoas.

Para Davenport (1998), o conhecimento é uma mistura fluída de experiência condensada, valores, informação contextual e insight experimentado, a qual proporciona uma estrutura para a avaliação e incorporação de novas experiências e informações. Ele tem origem e é aplicado na mente dos conhecedores. Nas organizações, ele costuma estar embutido nas rotinas, processos, práticas e normas organizacionais, bem como, nas atividades criadoras de conhecimento, que têm lugar dentro dos seres humanos e entre eles.

O processo de transformação da informação em conhecimento se dar através de:

- Comparação: de que forma as informações relativas a esta situação se comparam a outras situações conhecidas?

- Conseqüências: que implicações estas informações trazem para as tomadas de decisão e ações?

- Conexões: quais as relações deste novo conhecimento com o conhecimento já acumulado?

- Conversação: o que as outras pessoas pensam desta informação?

O conhecimento, para ser reconhecido como tal, tem de ter aprovação em termos de um critério de verdade socialmente aceito, com a avaliação formal de fatos ou apresentação de dados.

O conhecimento é decorrente da interpretação da informação e de sua utilização para gerar novas idéias, resolver problemas ou tomar decisões, e existe quando uma informação é explicada e suficientemente compreendida por alguém. Conhecimento também é o resultado de nossa aprendizagem, daquilo que experimentamos e podemos utilizar novamente em diversas situações.

Segundo Nonaka e Takeuchi (1997), existem diferenças entre conhecimento e informação. O conhecimento, ao contrário da informação, diz respeito a crenças e compromissos. O conhecimento é função de uma atitude, perspectiva ou intenção específica. O conhecimento está relacionado à ação, sempre com algum fim, ao contrário da informação.

Numa visão mais ampla do conceito de conhecimento, pode-se caracterizá-lo como explícito ou tácito. O conhecimento explícito é caracterizado pela codificação e transferência, e está nos documentos, base de dados, produtos e processos. O conhecimento tácito é difícil de codificar, é subjetivo, faz parte das ações, contextos e experiências pessoais. É o que sabemos, mas nem sempre conseguimos explicar.

Davenport e Prusak (1998) afirmam que o conhecimento existe dentro das pessoas, faz parte da complexidade e imprevisibilidade humana. Os ativos do conhecimento são mais difíceis de identificar. O conhecimento pode ser visto tanto como um processo quanto como um 
ativo. E para que a informação se transforme em conhecimento, os seres humanos precisam fazer todo o trabalho virtualmente.

Baseando-se nas visões de diversos autores, pode-se dizer que existem alguns fatores que levam ao sucesso dos projetos do conhecimento, tais como: uma cultura orientada para o conhecimento, a existência de uma infra-estrutura técnica e organizacional, o apoio da alta gerência, a vinculação ao valor econômico ou setorial, a orientação para processos, a clareza de visão e linguagem, elementos motivadores nãotriviais, algum nível da estrutura do conhecimento, como também múltiplos canais para a transferência do conhecimento.

Para Nonaka e Takeuchi (1997), o conhecimento pode ser dividido em conhecimento tácito e explícito. O conhecimento tácito é um conhecimento altamente pessoal e difícil de formalizar, o que dificulta sua transmissão e compartilhamento. Ele está profundamente enraizado nas ações e experiências de um indivíduo, bem como em suas emoções, valores, desejos ou ideais. Já o conhecimento explícito é expresso em palavras e números, facilmente comunicado e compartilhado sob a forma de dados brutos, fórmulas científicas, procedimentos codificados ou princípios universais, podendo ser facilmente processado por um computador, transmitido eletronicamente ou armazenado em banco de dados.

Na Teoria do Processo de Criação de Conhecimento desenvolvida por Nonaka e Takeuchi (1997), os autores colocam como pedra fundamental epistemológica a distinção entre o conhecimento tácito e o explícito. 0 segredo para a criação do conhecimento está na mobilização e conversão do conhecimento tácito.

O conhecimento tácito e o conhecimento explícito são mutuamente complementares. Eles interagem um com o outro e realizam trocas nas atividades criativas dos seres humanos.

O pressuposto de que o conhecimento é criado por meio da interação entre o conhecimento tácito e o conhecimento explícito fez Nonaka e Takeuchi (1997) postularem quatro modos diferentes de conversão do conhecimento, quais sejam:

- De conhecimento tácito em conhecimento tácito - Socialização;

- De conhecimento tácito em conhecimento explícito Externalização;

- De conhecimento explícito em conhecimento explicito Combinação;

- De conhecimento explícito em conhecimento tácito Internalização.

Compartilhar o conhecimento tácito é o objetivo da socialização, que isoladamente se constitui numa forma limitada de criação do conhecimento. A facilidade com que uma organização alavanca o conhecimento está diretamente relacionada com a eficiência da conversão do conhecimento tácito em conhecimento explícito. A criação do 
conhecimento organizacional é uma interação contínua e dinâmica entre o conhecimento tácito e o conhecimento explícito.

A socialização gera o conhecimento compartilhado; a externalização gera o conhecimento conceitual; a combinação dá origem ao conhecimento sistêmico; a internalização produz conhecimento operacional.

O conhecimento, dentro da organização, não é criado e desenvolvido sozinho. Criar conhecimento numa organização envolve a criação do conhecimento individual, que se amplia em comunidades de interação que transpassam seções, departamentos, divisões e organizações.

O conhecimento tácito criado e acumulado em nível individual deve ser mobilizado e ampliado organizacionalmente através dos quatro modos de conversão, constituindo a chamada espiral do conhecimento.

Nonaka e Takeuchi (1997) salientam que a função da organização no processo de criação do conhecimento organizacional é fornecer o contexto apropriado para a facilitação das atividades em grupos e para a criação e o acúmulo de conhecimento em nível individual. Colocam cinco condições em nível organizacional que promovem a espiral do conhecimento, sendo elas:

- Intenção: no desenvolvimento da capacidade organizacional de adquirir, criar, acumular e explorar o conhecimento, está a essência da criação do conhecimento organizacional - a estratégia. Conceituar uma visão e relacioná-la ao tipo de conhecimento que deve ser desenvolvido, e sua efetiva implementação, é o ponto crítico da estratégia da empresa que quer associar tecnologias essenciais e atividade de negócios;

- Autonomia: em nível individual, todos os membros de uma organização devem agir de forma autônoma conforme as circunstâncias. A postura empresarial que assegura a autonomia está mais propensa a manter maior flexibilidade ao adquirir, interpretar e relacionar informação;

- Flutuação e caos: essas condições estimulam a interação entre a organização e o ambiente externo. A introdução da flutuação numa empresa se dá por meio de colapsos de rotinas, hábitos ou estruturas cognitivas. Um processo contínuo de questionamento e reconsideração de premissas existentes estimula a criação do conhecimento;

- Redundância: no mundo dos negócios, a redundância refere-se à superposição intencional de informações sobre atividades da empresa e responsabilidades da gerência, e também sobre a empresa como um todo.

Os autores mostram que, para criar conhecimento dentro do contexto organizacional, é necessário que um conceito criado por um indivíduo ou por um grupo seja compartilhado por outros indivíduos que talvez não precisem do conceito imediatamente. O compartilhamento de informações redundantes promove o compartilhamento de conhecimento 
tácito, pois os indivíduos conseguem sentir o que os outros estão tentando expressar.

Variedades e requisitos: o enfrentamento dos desafios impostos por um ambiente de extrema complexidade é enormemente facilitado pela diversidade interna de uma organização. Esse ambiente de negócios requer o desenvolvimento de uma estrutura horizontal e flexível, na qual as diferentes unidades são interligadas por uma rede de informação.

A informação e o conhecimento são considerados fatores importantes no ambiente competitivo das organizações. Conhecimento não no sentido abstrato ou teórico, mas aplicado no dia-a-dia das empresas. Conhecimento sobre seu mercado, seus processos, seus clientes, sua tecnologia, seus concorrentes etc.

Percebe-se que existe a percepção comum de que a informação e o conhecimento são recursos essenciais para as organizações, e que, portanto, são recursos que precisam ser administrados em todos os setores da organização. Entretanto, a organização precisa de inteligência para usar de forma eficiente as informações e o conhecimento no processo de tomada de decisão.

\section{Modelos de busca e uso da informação}

\subsection{A busca e o uso da informação}

Viver na era do conhecimento é viver constantemente com um volume incalculável de informação que flui a uma velocidade imensa, sem uma percepção clara e de questionamento por parte da sociedade, e que, de certa forma, assume valores sociais e econômicos importantes, porque não dizer fundamentais.

A informação e o conhecimento tornaram-se os principais recursos econômicos para a competitividade das empresas. Porém, o excesso, o bombardeio crescente de informação, causado também pela variedade e celeridade dos meios de comunicação, reflete-se numa reação de estresse e perda de eficiência no trabalho, resultando num quadro em que a sobrecarga de informação pode redundar em desinformação, tendo em vista que o potencial de captação do homem - do ponto de vista físico, mental e psicológico - continua restrito.

Esse contexto é visto com grande preocupação, na medida em que, ao serem entendidas como recurso, as informações acarretam um crescimento no número de fontes, veículos e registros, que passam a exigir dos indivíduos da organização um gerenciamento eficaz sob pena de prejuízo competitivo.

A busca e o processamento da informação são essenciais em muitos sistemas sociais e atividades humanas, e a análise das necessidades e do uso da informação vem se tornando um componente importante de pesquisa em áreas como psicologia cognitiva, sistema de informação, tomada de decisão, difusão da inovação e aprendizagem organizacional. 
A literatura sobre estudos de usuário se insere em duas abordagens: a abordagem tradicional e a abordagem cognitiva. A abordagem tradicional objetiva melhorar a resposta do sistema e dos seus serviços, tendo como foco principal o sistema de informação. Considera a informação como externa, objetiva, alguma coisa que existe fora do indivíduo. Informação, nesse contexto tradicional, existe em um mundo ordenado e é capaz de ser descoberta, definida e medida. Pontos importantes desconsiderados nesta abordagem são os seguintes: o conhecimento não é absoluto, as pessoas mudam e a mensagem enviada não é idêntica à recebida (MORRIS, 1994).

Neste contexto, ignora-se o ser humano como um ser pensante, que cria sua própria realidade e tem suas informações internas armazenadas, as quais são usadas para compreender as informações externas e as diferentes situações em que ele (o indivíduo) se encontra em dado momento.

Entretanto, o comportamento de busca e uso de informação são também modelados pelo estilo cognitivo. A abordagem cognitiva se insere no paradigma centrado no usuário, que leva em consideração os sentimentos, a percepção, o modo como as pessoas aprendem, e também os aspectos do comportamento de busca e de uso de informação.

De uma maneira geral, os trabalhos sobre estudos de usuários da informação, inseridos dentro da abordagem cognitiva, possuem em comum as seguintes características: o foco principal está nos aspectos cognitivos e afetivos que interferem na busca e no uso da informação; a relevância das experiências individuais; o individuo como um ser humano ativo e criativo.

\subsection{O modelo ISP de busca de informação - (Information Search Process)}

A abordagem psicológica sobre a busca e o uso da informação no modelo ISP - Information Search Process é fundamentada em uma base teórica construtivista, nas áreas de Filosofia, com Dewey, sobre as Fases do Pensamento Reflexivo, de Psicologia com Kelly, sobre a Teoria do Constructo pessoal - PCT e de Educação com Bruner, sobre as fases de Aquisição do Conhecimento.

Kuhlthau (1994) buscou e adotou o conceito de "estados anômalos do conhecimento" de Belkin, Oddy e Brooks (1982), relacionado à necessidade de informação do usuário e, em Taylor (1968), buscou a teoria do focus Continuum, que é baseada na idéia de que o foco da necessidade de informação muda em uma perspectiva crescente e contínua.

O modelo ISP - Information Search Process - desenvolvido por Kuhlthau (1994) é caracterizado por mudanças nos estados físicos (ações), cognitivos (pensamentos) e afetivos (sentimentos), que levam os usuários a se comportarem e terem reações afetivas comuns. Em seu estudo sobre o comportamento de busca de informação, junto aos 
usuários de biblioteca e estudantes universitários, Kutlthau detectou padrões comuns na experiência dos usuários.

Para Kuhtlthau (1994), o modelo ISP é fortemente influenciado por teorias de aprendizagem construtivistas, para as quais a aprendizagem ocorre não pela transmissão, como no modelo comportamental, mas pela construção pessoal e ativa do novo conhecimento. Este modelo pressupõe que 0 indivíduo precise estar ativamente engajado para que a aprendizagem ocorra.

Alguns princípios distinguem o modelo ISP dos modelos tradicionais de pesquisa em bibliotecas.

- o papel ativo do bibliotecário na orientação e intervenção no processo de busca de informação;

- a parceria entre o professor e o bibliotecário no processo;

- a motivação para a pesquisa na biblioteca deve se configurar a partir de uma necessidade real de informação;

- a pesquisa deve gerar um produto final: uma apresentação oral, um artigo para publicação ou mesmo uma monografia;

- um trabalho de pesquisa não deve ser baseado apenas em anotações de sala de aula e/ou em apostilas;

- o uso da coleção de biblioteca (s)

O modelo apresenta seis estágios do processo de busca da informação: iniciação, seleção, exploração, formulação, coleta e apresentação. Cada processo de busca de informação caracteriza-se por comportamentos emocionais, cognitivos e físicos.

No primeiro estágio, segundo o modelo ISP, o estudante sente-se inseguro por não saber como começar e nem sobre o que pesquisar. Neste momento, quando ele se depara com uma nova idéia, sente-se confuso e inseguro. O sentimento de incerteza deverá acompanhar o estudante nos primeiros estágios, pelo menos até a delimitação do tema central, o que deverá ocorrer no quarto estágio. Kuhlthau (1994) recomenda que ainda neste estágio deva ter início a parceria professorbibliotecário, fundamental para o sucesso do processo.

No estágio seguinte, denominado de seleção do tema, o usuário deverá fazer uma busca preliminar no catálogo da biblioteca, nas estantes, nas obras de referência, para avaliar possíveis tópicos relacionados ao seu trabalho. Uma característica afetiva comum, nesse estágio, é a diminuição da ansiedade, que dará lugar ao otimismo, assim que o tópico tenha sido escolhido.

No terceiro estágio, denominado exploração do tópico, o estudante deve perscrutar o tópico escolhido (lendo e avaliando várias fontes gerais de informação - dicionários, enciclopédias, periódicos, etc) de maneira a escolher, dentre as várias facetas de uma área ou tópico, aquela que Ihe possibilite caminhar para a delimitação do tema ou a formulação do foco. A quantidade de informações encontradas e a ambigüidade natural delas provocam ansiedade e confusão nos estudantes. 
Estas atitudes são previsíveis e aceitas, em função da flexibilidade e interatividade do modelo, que permite reiniciar e repetir os estágios. É a possibilidade de avançar ou retornar conforme o ritmo de cada indivíduo, que garante que este modelo seja o caminho necessário e fundamental para uma aprendizagem autônoma e duradoura.

A formulação do foco no quarto estágio do processo é, segundo Kuhlthau (1994), o ponto crucial da busca de informação, mas nem sempre o usuário consegue alcançá-lo. Quando se depara com uma nova informação ou idéia, o usuário compara-a com as informações que ele já possui, reflete criticamente sobre ela de modo a decidir se a incorpora ou a descarta: a este processo denominou-se Formulação. É através da formulação que os pensamentos evoluem da dúvida para a compreensão.

Ao conseguir delimitar as fronteiras de sua pesquisa, o estudante será tomado por um grande sentimento de alívio. Quando o estudante não consegue delimitar sua pesquisa ele tem sérias dificuldades para concluíla, pois a qualidade do trabalho final está diretamente relacionada à compreensão do problema da pesquisa.

\subsection{Abordagem Sense - Making}

A abordagem Sense-Making, desenvolvida por Brenda Dervin (1986), evidencia que a realidade não é completa nem constante; ao contrário, é permeada de descontinuidades fundamentais e difusas, vazios (lacunas). A busca e o uso da informação são vistos como atividades construtivistas, como criação pessoal do sentido individual do ser humano. A informação não é algo que exista independente e externamente ao ser humano; ao contrário, é um produto da observação do ser humano sobre si próprio e sobre os outros.

A autora mostra que o comportamento dos indivíduos pode ser mais bem prognosticado a partir da estruturação de um modelo que focalize as situações de mudança, o modo como os indivíduos usam as informações, tanto de outras pessoas como as suas próprias, para construir sua realidade e direcionar seu comportamento.

A informação, afirma Dervin (1986), não é uma entidade independente da interação do homem com o mundo enquanto objeto do seu conhecimento. Também conhecida como abordagem da percepção do usuário, este estudo apresenta as seguintes características:

- Observar o ser humano como sendo construtivo e ativo.

- Considerar o indivíduo como sendo orientado simultaneamente.

- Visualizar holisticamente as experiências do indivíduo.

- Focalizar os aspectos cognitivos envolvidos.

- Analisar sistematicamente a individualidade das pessoas.

- Empregar maior orientação qualitativa.

Que informação um indivíduo quer encontrar no sistema de informação? Que uso fará dela? E como o sistema pode melhor ser projetado para preencher essas necessidades de informação? Esses 
questionamentos dependerão exclusivamente do próprio individuo, de seu propósito na busca de informação e no uso da mesma para a transposição das lacunas.

Para descrever padrões de busca de informação, deve-se admitir o indivíduo como o centro do fenômeno e considerar a visão, as necessidades, as opiniões e as dificuldades desse indivíduo como elementos significantes e influentes que merecem investigação.

Para o desenvolvimento do modelo Sense Making, cada momento será considerado um novo momento, mesmo que seja a repetição de comportamentos passados. Neste sentido, é importante observar como o indivíduo interpreta e transpõe este momento. Qual a estratégia usada para solucionar a situação que gerou a lacuna. Como ele interpreta esse problema e as possibilidades de resolvê-lo. Como se move taticamente para isso e como reinicia uma nova fase de busca da informação.

$\mathrm{Na}$ metáfora da criação de significado, o indivíduo move-se no espaço e no tempo, dando novos passos por meios de experiências vividas. Novos passos são dados a cada momento, mesmo que seja a repetição de uma ação já vivida. Para a autora, isto se constitui em um novo passo. Enquanto o indivíduo for capaz de construir significado irá existir a oportunidade de movimentar-se para frente.

Em uma situação problema, o movimento pode ser bloqueado, o indivíduo encontra lacunas que o levam a interromper seu caminho. Essa lacuna pode ser definida como um estado anômalo de conhecimento, um estado de incerteza, uma situação na qual um indivíduo está tentando chegar à compreensão de alguma coisa (DERVIN, 1986). O usuário identifica uma necessidade de informação quando sente uma lacuna entre seu estado atual e o estado desejado. Isso significa que ele procurará suprir essa necessidade, buscando informações a partir de, basicamente, quatro fontes: pessoais, comerciais, públicas ou experimentais.

A busca de informação e o uso da informação são analisados em termos do triângulo situação-vazio-uso, exemplificado pelas perguntas:

1. O que em sua situação está lhe bloqueando?

2. O que está faltando em sua situação?

3. Quais as suas dúvidas ou confusões?

4. Que tipo de ajuda você espera receber?

O estudo se caracteriza por apresentar uma entrevista de linha do tempo, em que a cada participante é solicitado reconstruir uma situação em termos dos acontecimentos e passos que formaram a linha do tempo da situação. Esse, por sua vez, descreve cada passo detalhadamente: como viu a situação, o vazio e a ajuda desejada. A entrevista feita dentro dos estudos de Sense-Making, das necessidades de informação de diferentes categorias de usuários, tem como característica perguntas que fazem referência a algum dos quatro momentos que formam a metáfora do Sense-Making: situação, gap, ponte (bridge), ajuda (help), representados da seguinte maneira: S B H G. 
Esses momentos situação-movimento-parada podem ser considerados como: esperando, enrolando, passando o tempo, obstaculizando, problematizando, sendo levado, decidindo, fracassando, paralisando, mexendo, observando ou desfrutando.

A perspectiva que o Sense-Making oferece para entender os processos de informação/comunicação tem como elemento principal o movimento, em que as entidades e os estados tornam-se processuais e dinâmicos, transformando os substantivos que identificam essas entidades/estados em verbos que indicam algum tipo de movimento.

O método de ir sempre na procura do gap ou da ponte entre a situação e a ajuda significa olhar para a situação problemática como um momento de decisão, em que as respostas às nossas perguntas vão sempre expressar confusão, idéias, emoções, sentimentos, perguntas e conclusões.

O instrumento de ajuda básico para a pesquisa de usuário no SenseMaking é a entrevista do micro-momento (DERVIN, 1986). Essa entrevista é formada por três passos básicos, que precisam estar sob o controle do entrevistador e do entrevistado:

1. narração de eventos ordenados no tempo ou sem ordenação;

2. expressão de confusões, idéias, emoções, sentimentos, perguntas e conclusões;

3. as respostas a perguntas tais como: o que ajudou você nesse momento? O que levou você a essa conclusão? Quais conexões você percebe? Como você quer ser ajudado agora?

As perguntas realizadas durante a entrevista, diferentemente da pesquisa demográfica, têm contida a visão de mundo do entrevistado e, se no lugar de criticar ou corrigir, o entrevistador organizar a fala em situação/gap/ajuda, obterá não unicamente o registro das emoções, mas também elementos para o desenho de uma base de dados sobre as necessidades de informação de um determinado tipo de comunidade.

\subsection{Modelo de uso da informação - Choo}

O modelo de uso de informação proposto por Choo (2003) identifica e relaciona os principais elementos que influenciam o comportamento do indivíduo quando busca e usa a informação. O modelo apresenta três estágios: a necessidade de informação, a busca de informação e o uso da informação. As bases conceituais do modelo apresentado por Choo estão na abordagem cognitiva de criação do significado, desenvolvida e aplicada por Brenda Dervin, nas reações emocionais que acompanham o processo de busca de informação, identificadas por Carol Kuhlthau, e nas dimensões situacionais do ambiente em que a informação é usada, proposta por Taylor (1986).

Para o autor, a necessidade de informação surge quando o indivíduo reconhece vazios em seu conhecimento e em sua capacidade de dar significado a uma experiência. No estágio da busca de informação, o 
individuo busca, intencionalmente, informações que possam mudar seu estado de conhecimento. Buscando a informação, o indivíduo faz uso da mesma a partir do momento em que ele seleciona e processa informações que produzem mudanças em sua capacidade de vivenciar e agir ou reagir a novos conhecimentos.

A forma como a informação ganha importância para o indivíduo dependerá das estruturas cognitivas e emocionais dele. A busca e o uso da informação fazem parte de uma atividade humana e social por meio da qual a informação pode tornar-se útil para o grupo ou para o individuo. 0 processo de busca e uso da informação é dinâmico e depende das condições em que o individuo ou o grupo a utiliza.

O modelo analisa o ambiente onde a informação é buscada, incluindo tanto o ambiente interno de processamento da informação, que está dentro do individuo, quanto o ambiente externo em que a informação é usada, que é o ambiente profissional do individuo.

A necessidade, a busca e o uso da informação ocorrem em ciclos recorrentes, que interagem sem ordem predeterminada. O processo de busca e uso da informação interage com elementos cognitivos, emocionais e situacionais do ambiente. Esses elementos animam continuamente o processo de busca da informação, alterando a percepção do individuo sobre o papel da informação e sobre seus comportamentos em relação a ela, como também os critérios pelos quais o valor da informação é julgado.

A necessidade de informação se filtra pelos vários níveis de consciência do indivíduo, do visceral ao consciente e ao formal. O indivíduo questiona-se através de perguntas ou tema formal capazes de representar adequadamente a necessidade de informação, podendo ser apresentada em um sistema de informação.

No estágio da busca de informação, o indivíduo desenvolve uma compreensão suficientemente clara da necessidade de informação, e pode ser influenciado por fatores cognitivos, emocionais e situacionais. Características profissionais e do meio social podem induzir ou restringir determinados comportamentos de busca da informação, como também a cultural empresarial, a estrutura hierárquica e o grupo de trabalho afetarão as atitudes do indivíduo em relação à coleta de informação.

O estado de espírito do indivíduo e a quantidade e originalidade da informação do usuário também podem influenciar a extensão e profundidade da busca. O indivíduo, ao encontrar uma informação e sentir confiança e otimismo, terá grande chance de prosseguir na busca.

O uso da informação é o estágio final do modelo. É a seleção e o processamento das informações que resultam em novos conhecimentos ou ações. O indivíduo, neste estágio, está atuando na informação encontrada, podendo responder ao seu questionamento, solucionar o problema, tomar decisões, negociar uma posição ou dar sentido a uma situação. O resultado do uso da informação se caracteriza pela mudança do estado de conhecimento do indivíduo e da sua capacidade de agir. Esse processo é contínuo e recorrente durante todo o processo de busca. A 
relevância da informação e o seu efetivo uso dependerão de como o indivíduo avalia cognitivamente e emocionalmente a informação recebida, como também dos atributos objetivos capazes de determinar a pertinência da informação a uma determinada situação problemática.

O modelo identifica oito classes de uso da informação: esclarecimento, compreensão do problema, instrumental, factual, confirmativa, projetiva, motivacional e pessoal ou política. O uso da informação é visto como uma ajuda que o indivíduo deseja obter da informação para continuar em sua trajetória de vida. A partir do momento em que a busca consegue produzir informações satisfatórias, o indivíduo apresenta sentimento de confiança. Por outro lado, se a informação não for útil, o resultado são sentimentos de decepção e frustração.

\section{Considerações Finais}

As organizações vivenciam um momento de profunda mudança, diante de uma nova era imposta pela sociedade da informação. Nessa mudança, o novo paradigma é a informação, e o conhecimento que permite uma nova visão de negócios, facilitando a tomada de decisão e possibilitando um reposicionamento das estratégias de negócios.

$\mathrm{Na}$ maioria das organizações, os tomadores de decisões freqüentemente trabalham com grande quantidade de dados em estado bruto, pequena quantidade de informação com valor agregado e pouco conhecimento adquirido para a tomada de decisão. A mudança no processo de tomada de decisão baseia-se numa abordagem com ênfase na informação e no conhecimento, considerando que o diferencial seja a detecção e o gerenciamento da informação eficaz, através do processo de busca, seleção, análise, disseminação e transformação dessa informação em conhecimento, com o objetivo de obter um melhor posicionamento no espaço competitivo no qual atua, como também de oferecer subsídio para que estas organizações possam conscientemente se adaptar às exigências do ambiente no qual estão inseridas.

\section{Referências}

BARRETO, A. A. A questão da informação. São Paulo em Perspectiva: Revista da Fundação SEADE, São Paulo, v. 8, n. 4, p. 3-8, out./dez. 1994.

BARTOLOMÉ, F. Comunicação eficaz na empresa: como melhorar o fluxo de informações para tomar decisões corretas. In: HARVARD Business Review Book. Rio de Janeiro: Campus, 1999.

BELKIN, N. J.; ODDY, B. N.; BROOKS, H. M. ASK for information retrieval: background and theory. Journal of Documentation, London, v. 38, n. 2, p. 61-71, June, 1982.

CHOO, W. C. A organização do conhecimento: como as organizações usam a informação para criar significado. São Paulo: Senac, 2003. 
DAVENPORT, T.; PRUSAK, L. Conhecimento empresarial: como as organizações gerenciam o seu capital intelectual. Rio de Janeiro: Campus, 1998.

DERVIN, B. Information needs and uses. Annual review of information science an technology, New York, v. 21, p. 3-33, 1986.

DRUCKER, P. F. O advento da nova organização. In: HARVARD Business Review. Rio de Janeiro: Campus, 2000. p. 09-26.

KUHLTHAU, C. C. Seeking meaning: a process approach to library and information services. New Jersey: Ablex, 1994.

McGEE, J.; PRUSAK, L. Gerenciamento estratégico da informação: aumente a competitividade e a eficiência de sua empresa utilizando a informação como uma ferramenta estratégica. Rio de Janeiro: Campus, 1994.

MORRIS, J.A; FELDMAN, D.C. The dimensions, antecedents and consequences of emotional labor. The Academy of Management Review, v. 21, n. 4, p. 986-1010, Oct. 1994.

NONAKA, I. Criação do conhecimento na empresa. Rio de Janeiro: Campus, 2000.

NONAKA, I.; TAKEUCHI, H. Criação de conhecimento na empresa como as empresas japonesas geram a dinâmica da inovação. Rio de Janeiro: Campus, 1997.

SETZER; F.S.C. Silva. Bancos de dados: aprenda o que são, melhore seu conhecimento, construa os seus. São Paulo: E. Blücher, 2005.

SPENDER, J. C. Gerenciando sistemas de conhecimento. In: FLEURY, M. T. L.; OLIVEIRA JR., M. M. (Orgs.). Gestão estratégica do conhecimento. São Paulo: Atlas, 2001. p. 28-49.

STAIR, M. R. Princípios de sistema de informação: uma abordagem gerencial. 2. ed. Rio de Janeiro: LTC, 1998.

TAYLOR, R. S. Questions negociation and information seeking in libraries. College \& Research Libraries, Chicago, v. 29, p. 178-194, 1986.

WURMAN, R. S. Ansiedade de informação: como transformar informação em compreensão. São Paulo: Cultura Editores Associados, 1997. 